\title{
Ultrasound evaluation of carotid artery intima-media thickness in patients with risk factors for cardiovascular disease
}

\author{
Ibrahim A. Awad, Hanan Y. Abbas* \\ Diagnostic Radiology Department, Faculty of Applied Medical Sciences, King Abdulaziz University, KSA
}

Received: November 18, 2016

DOI: $10.5430 /$ ijdi.v4n2p16
Accepted: January 31, 2017

Online Published: March 20, 2017

\begin{abstract}
Objective: The study purpose was to assess the change of carotid artery intima-media thickness (CAIMT) in patients with cardiovascular risk factors (CVRF), and determine the main factor that causing the abnormal IMT.

Methods: We collected the data of 89 patients who underwent a carotid artery ultrasound between February 2011 and November 2012 (43 men and 46 women aged between 20-80 years old). All patients included in the study had one of the following cardiovascular risk factors: smoking $(n=40)$, arterial hypertension $(n=25)$ or diabetes mellitus $(n=24)$. The IMT of the common carotid artery was measured and the results were correlated with the recorded risk factor. Correlation with the patient's age and gender was also performed.

Results: The study revealed abnormal IMT (>1 mm) in a total of $71(79.8 \%)$ patients. These included $22(88 \%)$ patients with hypertension, 19 (79.2\%) patients with diabetes mellitus and 30 (75\%) patients who were smokers $(p<.05$ for all 3 risk factors). While aging was also associated with increased IMT $(p<.05)$, no gender differences were noted $(p>.05)$.

Conclusions: The present study showed that ultrasound is an excellent, noninvasive method for evaluation of carotid intima-media thickness. The main risk factors associated with abnormal carotid IMT were hypertension, diabetes mellitus, smoking and patient's age.
\end{abstract}

Key Words: B-mode ultrasound, Intima-media thickness

\section{INTRODUCTION}

The carotid artery intima-media thickness (IMT) is increasingly been used as an important parameter in many studies evaluating heart disease and vascular atherosclerosis. ${ }^{[1]}$ Nonlinear relationships between increased carotid artery IMT and increased risk of stroke and cardiac events have been demonstrated. ${ }^{[2,3]}$ A distinct relationship between the severity of atherosclerosis in one artery and the involvement of other arterial beds has also been shown. ${ }^{[2]}$ Therefore non-invasive measurement of intima-media thickness of peripheral arteries, particularly of carotid arteries, is being considered for early detection of arterial disease, including for evaluation of atherosclerotic plaques and arterial wall smooth muscle enlargement. Values of carotid artery IMT above $0.9 \mathrm{~mm}$ are considered abnormal and values higher than $1 \mathrm{~mm}$ correlate with increased incidence of atherosclerosis and cardiovascular events..$^{[4,5]}$

The B-mode carotid ultrasonography represents a sensitive

\footnotetext{
${ }^{*}$ Correspondence: Hanan Y. Abbas; Email: habbas1@kau.edu.sa; Address: Diagnostic Radiology Department, Faculty of Applied Medical Science, King Abdulaziz University, Jeddah 21589, KSA. 
modality used for measuring the thickness of the tunica intima and media of the carotid arteries. The sensitivity and accuracy of the test increase when the measurements are taken in multiple areas of the common carotid arteries. ${ }^{[4]}$ Although both the near and the far wall images of the carotid artery can be obtained, ${ }^{[5,6]}$ the thickness of the intima-media complex is reported to be more accurate when measured in the far wall position. ${ }^{[7]}$

\section{MATERIALS AND METHODS}

The data of 99 consecutive patients who underwent a carotid artery ultrasound exam between February 2011 and November 2012 were retrospectively reviewed. From these, 10 patients had more than one cardiovascular risk factor and were excluded from the study. The rest of 89 patients who were included in the study ( 43 men and 46 women aged between 20-80 years old, the mean age representing 61.0 years) had one of the following cardiovascular risk factors: smoking $(\mathrm{n}=40)$, arterial hypertension $(\mathrm{n}=25)$ or diabetes mellitus ( $\mathrm{n}$ $=24)$. The study demographic data are also shown in Table 1.

Table 1. Demographic data of the study population

\begin{tabular}{lll}
\hline & Frequency & Percent \\
\hline Male & 43 & $48.3 \%$ \\
Female & 46 & $51.7 \%$ \\
Total & 89 & $100 \%$ \\
\hline
\end{tabular}

All patients were examined using a high frequency 5-12 $\mathrm{MHz}$ linear array transducer (IU22 Philips system). The intima-media thickness (IMT) of the common carotid artery was measured bilaterally by an experienced sonographer and values above $1 \mathrm{~mm}$ were considered abnormal (see Figure 1). The results were correlated with the recorded risk factor. Correlation with the patient's age and gender was also performed.
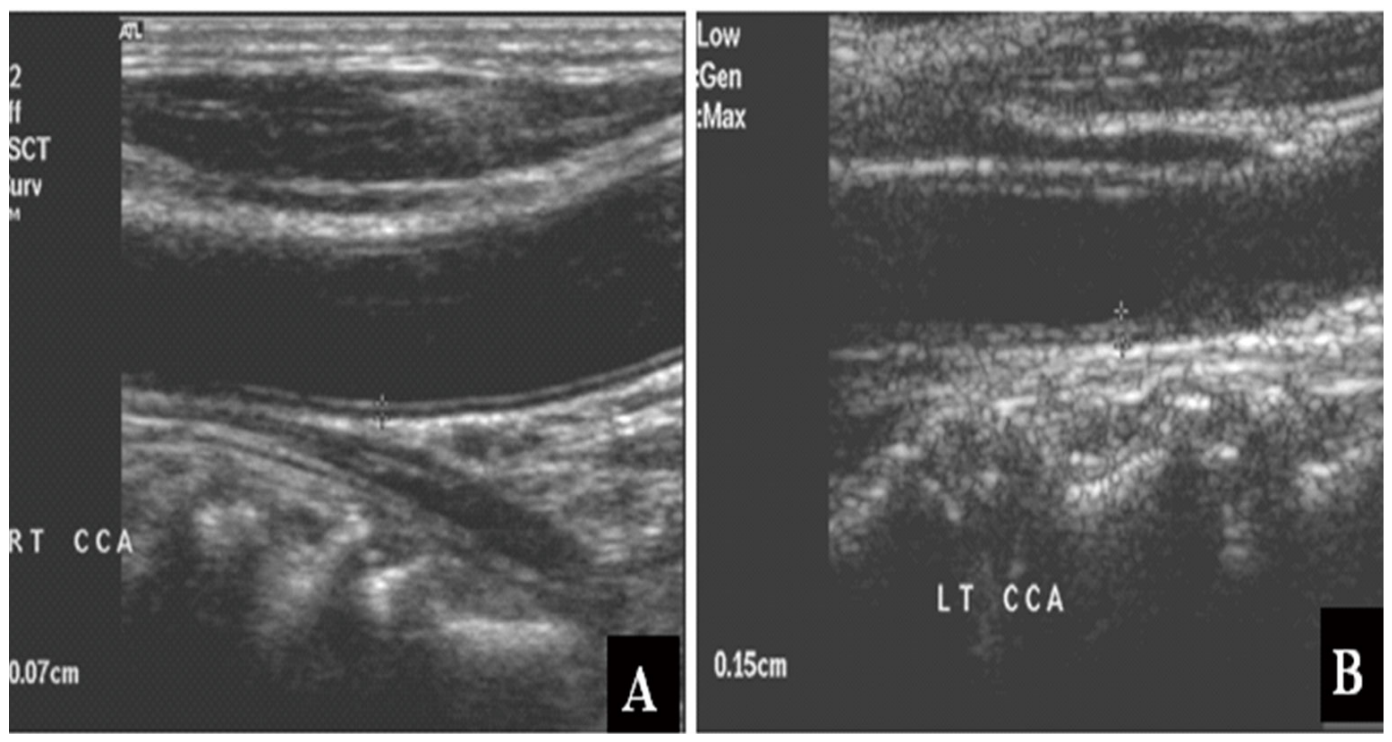

Figure 1. Carotid longitudinal ultrasound images. A. Normal smooth carotid intima-media of $0.07 \mathrm{~cm}$; B. Abnormal moderate intimal thickening of $0.15 \mathrm{~cm}$

Table 2. Distribution of risk factors and carotid IMT data obtained by ultrasonography

\begin{tabular}{llll}
\hline Clinical & \multicolumn{4}{l}{ Abnormal IMT } & Normal IMT Number of patients \\
\hline SMOKING & 30 & 10 & 40 \\
DM & 19 & 5 & 24 \\
HTN & 22 & 3 & 25 \\
TOTAL & 71 & 18 & 89 \\
\hline
\end{tabular}

The statistical analysis was performed using an SPSS program for Windows, version 19 software package (IBM Company, New York, USA). Categorical variables were analyzed

Published by Sciedu Press using a Chi-square test $\left(\mathrm{X}^{2}\right)$ or Fischer's exact test for small samples. A $p$-value $<.05$ was considered significant.

The study was approved by the Research Ethics Committee of the King Abdul-Aziz University, Faculty of Medicine.

\section{RESULTS}

The study data were evaluated separately for patients presenting with different cardiovascular risk factors. The results revealed significant associations between the present risk factors and abnormal carotid IMT. Thus, abnormal values of intima-media thickness exceeding $1 \mathrm{~mm}$ were revealed in $75 \%$ of smokers (30 from 40 subjects, $p=.004$ ), $79.2 \%$ of 
patients with diabetes mellitus ( 19 from 24 subjects, $p=.013$ ) provided in Table 2 and Figure 2.

and $88 \%$ of patients with systemic arterial hypertension $(22$

from 25 subjects, $p<.001)$. A summary of these results is

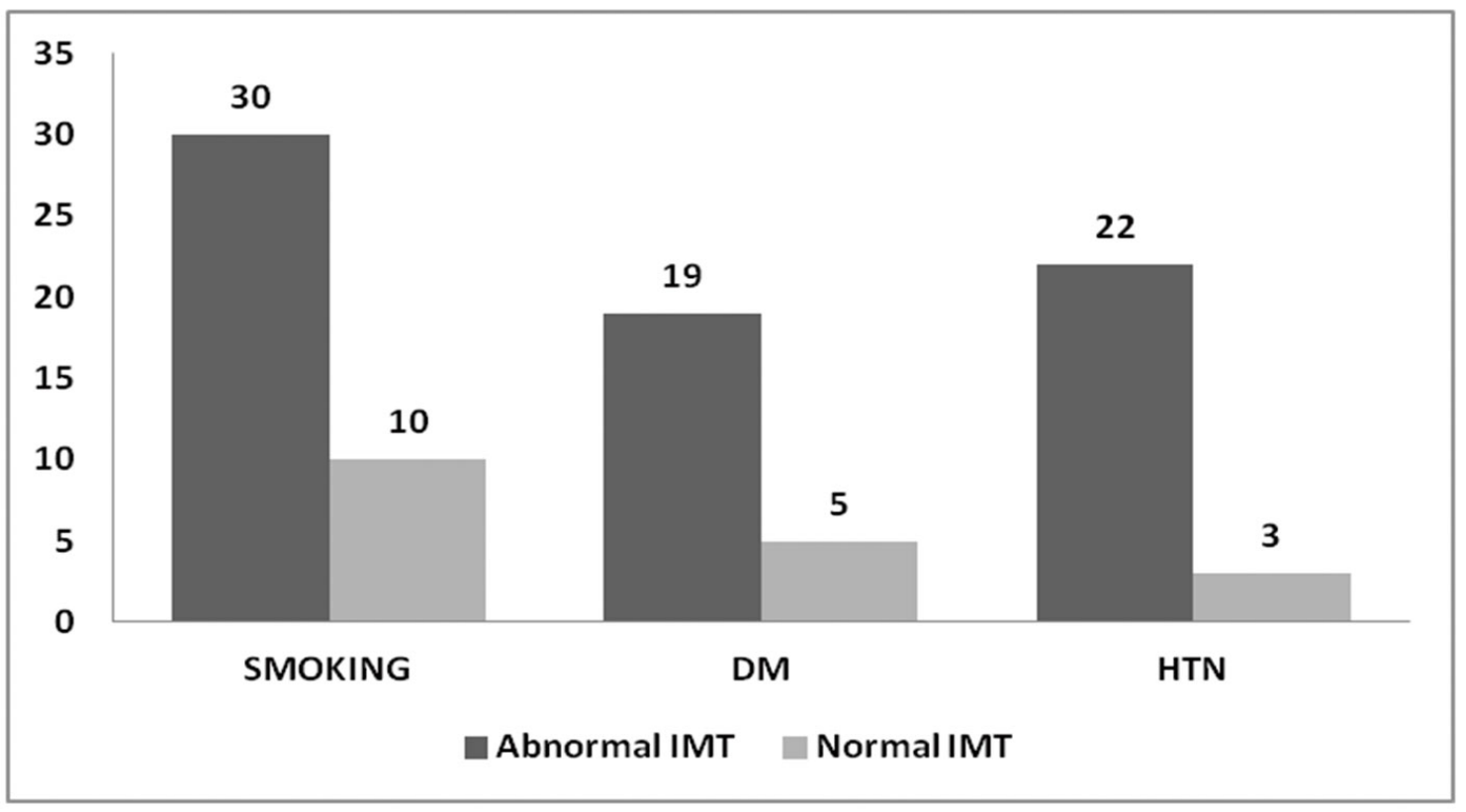

Figure 2. Distribution of the study population $(n=89$ patients $)$ according to the present risk factors and carotid IMT data obtained by ultrasonography. The figures above the columns reflect the number of patients

A separate analysis of the obtained data revealed additional correlations between carotid IMT and patient's age. Thus, subjects younger than 40 years represented less than $6 \%$ of patients with abnormal IMT, while subjects older than 50 years represented over $80 \%$ of patients with abnormal IMT (see Table 3). At the same time, no significant gender differences were noted $(p>.05)$.

Table 3. Recorded abnormal IMT values in different age groups

\begin{tabular}{lll}
\hline Age groups & Number of patients & Percentage \\
\hline $20-40$ yrs & 4 & $5.6 \%$ \\
$41-50$ yrs & 9 & $12.7 \%$ \\
$51-60$ yrs & 18 & $25.3 \%$ \\
$61-70$ yrs & 19 & $26.8 \%$ \\
$71-80$ yrs & 21 & $29.6 \%$ \\
Total & 71 & $100 \%$ \\
\hline
\end{tabular}

\section{Discussion}

The carotid thickness of the intima-media layer is an important marker for atherosclerosis and can indicate the presence of a disease process. Being an independent predictive marker of stroke and cardiovascular events, IMT can play an important role in assessing the risk for cardiovascular disease. ${ }^{[8]}$

Although different risk factors may affect the intima-media thickness, our results suggest that systemic arterial hyperten18 sion, smoking, and diabetes have the greatest impact. Thus, in our study as many as $88 \%$ of patients with arterial hypertension demonstrated abnormal carotid IMT. The results are in agreement with previous reports indicating that IMT is positively correlated with blood pressure variability in patients with hypertension. ${ }^{[9,10]}$

Even though a number of previous studies also report potential gender differences in the distribution and the determinants of atherosclerosis, ${ }^{[11-13]}$ our data revealed no significant differences between males and females. This may be related to the particularities of our study population, including ethnical characteristics as well as to a relatively small sample size.

\section{Conclusion}

The present study showed that ultrasound is an excellent, noninvasive method for evaluation of carotid intima-media thickness. The main risk factors associated with abnormal carotid IMT were hypertension, diabetes mellitus, smoking and patient's age. No gender differences were noted; however, this may be related to the particularities of our study population and new studies including larger cohorts of different ethnical background may bring further clarifications.

\section{CONFlicts OF INTEREST Disclosure}

The authors have declared no conflicts of interest. ISSN 2331-5857 E-ISSN 2331-5865 


\section{REFERENCES}

[1] Filippo M, Jasjit SS, Chirinjeev K. Atherosclerosis Disease Management. Berlin: Springer, ISBN; 2010: 1-4419-7221-8.

[2] O'Leary DH, Polak JF, Kronmal RA, et al. Carotid-artery intima and media thickness as a risk factor for myocardial infarction and stroke in older adults. Cardiovascular Health Study Collaborative Research Group. N Engl J Med. 1999; 340: 14-22. PMid:9878640 https://doi.org/10.1056/NEJM199901073400103

[3] Chambless LE, Heiss G, Folsom AR, et al. Association of coronary heart disease incidence with carotid arterial wall thickness and major risk factors: the Atherosclerosis Risk in Communities (ARIC) Study, 1987-1993. Am J Epidemiol. 1997; 146: 483-494. PMid:9290509 https://doi.org/10.1093/oxfordjournals.aje.a009302

[4] Simon A, Gariepy J, Chironi G, et al. Intima-media thickness: A new tool for diagnosis and treatment of cardiovascular risk. J Hypertens. 2002; 20: 159-69. PMid:11821696 https ://doi .org/10.1097/ 00004872-200202000-00001

[5] Wikstrand J, Wendelhag I. Methodological considerations of ultrasound investigation of intima-media thickness and lumen diameter. J Intern Med. 1994; 236: 555-9. PMid:7964433 https: //doi.org/10.1111/j.1365-2796.1994.tb00845.x

[6] Wong M, Edelstein J, Wollman J, et al. Ultrasonic-pathological comparison of the human arterial wall.Verification of intima-media thickness. Arterioscler Thromb. 1993; 13: 482-6. PMid:8466883 https://doi.org/10.1161/01.ATV.13.4.482

[7] Wikstrand J. Methodological considerations of ultrasound measurement of carotid artery intima-media thickness and lumen diameter. Clin Physiol Funct Imaging. 2007; 27(6): 341-5. PMid:17944655 https://doi.org/10.1111/j.1475-097X.2007.00757.x
[8] Aguilar-Shea AL, Gallardo-Mayo C, Garrido-Elustondo S, et al. Carotid intima-media thickness as a screening tool in cardiovascular primary prevention. Eur J Clin Invest. 2011; 41: 521-6. PMid:21155766 https ://doi.org/10.1111/j.1365-2362.20 10.02440.x

[9] Pall D, Settakis G, Katona E, et al. Increased common carotid artery intima media thickness in adolescent hypertension: results from the Debrecen Hypertension study. Cerebrovasc Dis. 2003; 15: 167-172. PMid:12646774 https://doi.org/10.1159/000068834

[10] Mancia G, Parati G, Hennig M, et al. Relation between blood pressure variability and carotid artery damage in hypertension: baseline data from the European Lacidipine Study on Atherosclerosis (ELSA). J Hypertens. 2001; 19: 1981-1989. PMid:11677363 https : //doi.org/10.1097/00004872-200111000-00008

[11] Stensland-Bugge E, Bønaa KH, Joakimsen O. Age and sex differences in the relationship between inherited and lifestyle risk factors and subclinical carotid atherosclerosis: the Troms $\emptyset$ study. Atherosclerosis. 2001; 154: 437-448. https : //doi .org/10.1016/S0021-9 150 (00) 00486-X

[12] Tan TY, Lu CH, Lin TK, et al. Factors associated with gender difference in the intima-media thickness of the common carotid artery. Clin Radiol. 2009; 64: 1097-1103. PMid:19822243 https : //doi.org/10.1016/j.crad.2009.06.009

[13] Kablak-Ziembicka A, Przewlocki T, Tracz W, et al. Gender differences in carotid intima-media thickness in patients with suspected coronary artery disease. Am J Cardiol. 2005; 96: 1217-1222. PMid:16253585 https://doi.org/10.1016/j.amjcard. 2005 .06 .059 